\title{
Republication: All India Difficult Airway Association 2016 Guidelines for Tracheal Intubation in the Intensive Care Unit
}

\begin{abstract}
Sheila Nainan Myatra, Syed Moied Ahmed ${ }^{1}$, Pankaj Kundra², Rakesh Garg ${ }^{3}$, Venkateswaran Ramkumar ${ }^{4}$, Apeksh Patwa ${ }^{5}$, Amit Shah $^{5}$, Ubaradka S. Raveendra ${ }^{6}$, Sumalatha Radhakrishna Shetty ${ }^{6}$, Jeson Rajan Doctor, Dilip K. Pawar ${ }^{7}$, Singaravelu Ramesh ${ }^{8}$, Sabyasachi Das ${ }^{9}$, Jigeeshu Vasishtha Divatia

Department of Anaesthesiology, Critical Care and Pain, Tata Memorial Hospital, Mumbai, Maharashtra, 'Department of Anaesthesiology and Critical Care, J N Medical College and Hospital, AMU, Aligarh, Uttar Pradesh, ${ }^{2}$ Department of Anaesthesiology and Critical Care, JPPMER, Puducherry, ${ }^{3}$ Department of Onco-Anaesthesiology and Palliative Medicine, Dr BRAIRCH, All India Institute of Medical Sciences, ${ }^{7}$ Department of Anaesthesiology, Critical Care and Pain, All India Institute of Medical Sciences, New Delhi, ${ }^{4}$ Department of Anaesthesiology, Kasturba Medical College, Manipal, ${ }^{6}$ Department of Anaesthesiology and Critical Care, K S Hegde Medical Academy, Nitte University, Mangalore, Karnataka, ${ }^{5}$ Kailash Cancer Hospital and Research Centre, Vadodara Institute of Neurological Sciences, Vadodara, Gujarat, ${ }^{8}$ Department of Paediatric Anaesthesia, Kanchi Kamakoti Childs Trust Hospital, Chennai, Tamil Nadu, ${ }^{9}$ Department of Anaesthesiology, North Bengal Medical College, Darjeeling, West Bengal, India
\end{abstract}

These guidelines have been reproduced with permission from the Indian Journal of Anaesthesia: Indian J Anaesth 2016;60:922-930

\section{Abstract}

Tracheal intubation (TI) is a routine procedure in the Intensive Care Unit (ICU) and is often lifesaving. In contrast to the controlled conditions in the operating room, critically ill patients with respiratory failure and shock are physiologically unstable. These factors, along with under evaluation of the airway and suboptimal response to preoxygenation, are responsible for a high incidence of life-threatening complications such as severe hypoxemia and cardiovascular collapse during TI in the ICU. The All India Difficult Airway Association (AIDAA) proposes a stepwise plan for safe management of the airway in critically ill patients. These guidelines have been developed based on available evidence; Wherever, robust evidence was lacking, recommendations were arrived at by consensus opinion of airway experts, incorporating the responses to a questionnaire sent to members of the (AIDAA) and Indian Society of Anaesthesiologists. Noninvasive positive pressure ventilation for preoxygenation provides adequate oxygen stores during TI for patients with respiratory pathology. Nasal insufflation of oxygen at $15 \mathrm{~L} / \mathrm{min}$ can increase the duration of apnea before hypoxemia sets in. High flow nasal cannula oxygenation at 60-70 L/min may also increase safety during intubation of critically ill patients. Stable hemodynamics and gas exchange must be maintained during rapid sequence induction. It is necessary to implement an intubation protocol during routine airway management in the ICU. Adherence to a plan for difficult airway management incorporating the use of intubation aids and airway rescue devices and strategies is useful.

Keywords: Complications, emergency department, intensive care, intubation bundle, ketamine, noninvasive positive pressure ventilation, tracheal intubation

\section{INTRODUCTION}

Difficult intubations are common in the Intensive Care Unit (ICU), emergency department (ED), and prehospital settings, with the incidence ranging being between $8 \%$ and $13 \% .^{[1-5]}$

Compromised cardiorespiratory physiology, risk of aspiration, and the presence of specific factors related to the environment and inadequately trained operators render tracheal intubation (TI) in the ICU more likely to be associated with complications compared to that in the operating room (OR). Unlike in the OR, postponing airway

\begin{tabular}{|l|l|}
\hline \multicolumn{3}{c|}{ Access this article online } \\
\hline Quick Response Code: & Website: \\
& www.ijccm.org \\
\cline { 2 - 2 } & \\
\hline
\end{tabular}

management is not an option in critically ill patients who need a definite airway to be secured at the earliest. ${ }^{[6]}$ The Fourth National Audit Project (NAP4) report of the Royal College of Anaesthesiologist and the Difficult Airway Society ${ }^{[7]}$ found

Address for correspondence: Prof. Jigeeshu Vasishtha Divatia, Department of Anesthesiology, Critical Care and Pain, Tata Memorial Hospital, Dr. Ernest Borges Road, Parel, Mumbai - 400012 ,

Maharashtra, India. E-mail: jdivatia@yahoo.com

This is an open access article distributed under the terms of the Creative Commons Attribution-NonCommercial-ShareAlike 3.0 License, which allows others to remix, tweak, and build upon the work non-commercially, as long as the author is credited and the new creations are licensed under the identical terms.

For reprints contact: reprints@medknow.com

How to cite this article: Myatra SN, Ahmed SM, Kundra P, Garg R, Ramkumar V, Patwa A, et al. Republication: All India difficult airway association 2016 guidelines for tracheal intubation in the intensive care unit. Indian J Crit Care Med 2017;21:146-53. 
that more than $60 \%$ airway complications in the ICU led to death or brain damage compared with $14 \%$ in anesthesia. Several evidence-based strategies have been proposed to improve the safety and outcome of TI in ICU. The All India Difficult Airway Association (AIDAA), therefore, developed guidelines provide a stepwise approach to TI in ICU with the goal of improving safety and outcomes in ICU patients. These guidelines neither represent the minimum standard of practice, nor are they a substitution for good clinical judgment. These guidelines should be used in conjunction with "The AIDAA 2016 Guidelines for the Management of the Unanticipated Difficult Intubation in Adults." ${ }^{[8]}$

\section{Methods}

The methodology adopted for the development of AIDAA guidelines, including anticipated difficult extubation guidelines has been described previously. ${ }^{[8]}$ A thorough literature search was done using databases/search engine (Medline, PubMed, Google Scholar, and websites of National Societies for airway guidelines) till September 2016. The articles were manually searched from cross-referencing. All manuscripts and abstracts published in English were searched. The key words used included "intubation, intensive care, critical care, critically ill, complications, cardiovascular, preoxygenation, high-flow nasal cannula." For areas that did not have robust evidence, opinions of experts, and members of the societies were taken regarding issues related to TI in the ICU.

\section{Challenges and Complications during Tracheal IntUbation In the Intensive Care Unit}

There are several factors that make TI more challenging in ICU as compared to that in the OR [Table 1].
The incidence of complications during intubation in critically ill patients in the ICU and ED ranges from $22 \%$ to $54 \%$, making emergency intubation a very high-risk procedure. Table 2 summarizes the incidence of serious complications observed in some studies..$^{[1-3,9-13]}$ Two or more attempts at TI significantly increase the risk of complications. ${ }^{[3,14]}$ In one study, complication rates in patients in whom two or more attempts were required, compared to those in whom intubation was successful at the first attempt, were aspiration (22\% vs. $2 \%)$, hypoxemia (70\% vs. $12 \%$ ), and cardiac arrest (11\% vs. $1 \%){ }^{[9]}$ These findings highlight the importance of improving the first attempt success in critically ill patients. ${ }^{[14]}$ The occurrence of aspiration and hypoxemia during emergency intubations increased the risk of developing a cardiac arrest by 22 and four times, respectively. An esophageal intubation was the most common cause of cardiac arrest and was associated with a seven-fold increase in the risk of death. ${ }^{[15]}$

\section{Predicting Difficult Intubation in Intensive Care UNIT}

Most conventional tests used at predicting difficult airway, ${ }^{[16,17]}$ focus on anatomical features that make glottic visualization difficult and are difficult to perform in patients requiring during emergency intubation. ${ }^{[18]}$ The MACOCHA score ${ }^{[19]}$ has been recently developed to identify patients with potentially difficult airway in the ICU. This score not only considers patient-related anatomical difficulty but also physiological factors and operator experience. The components of the score are the presence of a Mallampati score of III or IV scoring five points, obstructive sleep apnea scoring two points and cervical immobility, limited mouth opening, coma, severe hypoxemia,

\begin{tabular}{|c|c|}
\hline Factors & Challenges \\
\hline \multicolumn{2}{|l|}{ ICU-related factors } \\
\hline Infrastructure & $\begin{array}{l}\text { Lack of space around the patient, poor access to patient's head end, poor lighting, trained help may not be } \\
\text { available }\end{array}$ \\
\hline Equipment & $\begin{array}{l}\text { Airway devices such as fiber-optic bronchoscope, supraglottic airways, videolaryngoscope, etc., may not } \\
\text { be readily available in the ICU }\end{array}$ \\
\hline Timing & Emergency intubation may be required at any time in the day or night \\
\hline \multicolumn{2}{|l|}{ Patient factors } \\
\hline Airway assessment & Difficult or impossible due to lack of time or patient being uncooperative \\
\hline Risk of aspiration & $\begin{array}{l}\text { Full stomach, gastroparesis associated with critical illness or patient not fasted and requiring emergency } \\
\text { intubation }\end{array}$ \\
\hline Challenging anatomy & Maxillofacial trauma, cervical spine injury, airway injuries, burns, retropharyngeal abscess, etc. \\
\hline Inefficient preoxygenation & Shunt, ventilation-perfusion mismatch from the underlying illness, reduced functional residual capacity \\
\hline Rapid desaturation & lack of physiological reserve often leads to rapid hypoxemia \\
\hline Hemodynamic instability & Due to critical illness or use drugs used to facilitate intubation \\
\hline Waking up the patient is not an option & $\begin{array}{l}\text { Unlike in the operating room, waking up the patient and postponing airway management when a difficult } \\
\text { airway is encountered is often not possible, as the critical illness mandates a definitive airway }\end{array}$ \\
\hline \multicolumn{2}{|l|}{ Operator factors } \\
\hline Training & Limited airway training and poor airway management skills \\
\hline Experience & Inexperienced junior doctors may be performing intubation alone \\
\hline Stress & $\begin{array}{l}\text { Any of the patient, ICU or operator related factors, alone or in combination may produce stressful } \\
\text { situation }\end{array}$ \\
\hline
\end{tabular}

ICU: Intensive Care Unit 
Myatra, et al.: Tracheal intubation in the ICU

\begin{tabular}{|c|c|c|c|c|c|c|}
\hline Author & $\begin{array}{l}\text { Difficult intubation or multiple } \\
\text { attempts (\% patients) }\end{array}$ & $\begin{array}{l}\text { Severe hypoxia } \\
\text { (\% patients) }\end{array}$ & $\begin{array}{l}\text { Hypotension } \\
\text { (\% patients) }\end{array}$ & $\begin{array}{c}\text { Esophageal intubation } \\
\text { (\% patients) }\end{array}$ & $\begin{array}{l}\text { Aspiration } \\
\text { (\% patients) }\end{array}$ & $\begin{array}{l}\text { Cardiac arrest } \\
\text { (\% patients) }\end{array}$ \\
\hline Schwartz et al.$^{[1]}$ & 8 & - & - & 8 & 4 & 3 \\
\hline Jaber et al..$^{[2]}$ & 12 & 26 & 25 & 4.6 & 2 & 2 \\
\hline Griesdale et al. ${ }^{[3]}$ & 13.2 & 19.1 & 9.6 & 7.4 & 5.9 & 0 \\
\hline $\operatorname{Mort}^{[9]}$ & 10 & 4.7 & - & 9.7 & 2.1 & 1.8 \\
\hline Martin et al. ${ }^{[10]}$ & 10.3 & - & - & 1.3 & 2.8 & - \\
\hline Mayo et al..$^{[11]}$ & 20 & 14 & 6 & 11 & 2 & 1 \\
\hline Bowles et al. ${ }^{[12]}$ & 9 & 14 & 26 & 1 & 5 & 1 \\
\hline Simpson et al. ${ }^{[13]}$ & 0 & 22 & 20 & 2 & - & - \\
\hline
\end{tabular}

and a nonanesthetist operator scoring one point each. The score thus has a maximum of 12 points, with zero points predicting an easy intubation and 12 points predicting a very difficult one. This test has a sensitivity of $73 \%$ and has not been validated for video laryngoscopy. ${ }^{[19]}$

\section{Special Considerations during Tracheal Intubation in InTensive Care Unit \\ Presence of two operators (one experienced in airway management)}

Studies suggest that the presence of an experienced operator during airway management, and supervision of junior doctors performing intubation by a senior consultant, can help reduce complications during TI in ICU. ${ }^{[2,20]}$ Based on the available data, we recommend the presence of two operators during ICU intubations, with one being experienced in airway management.

\section{Calling for help}

In addition to the two operators present during intubation, we recommend calling for additional help at the earliest, when the first difficulty in airway management is encountered. We also recommend calling for additional help when the final attempt at rescue mask ventilation fails and emergency cricothyroidotomy is planned. An additional person, who has not been part of the process until then, may be able to think more rationally and perform better in this situation, in addition to being an extra helping hand.

\section{Preoxygenation and peri-intubation oxygenation in Intensive Care Unit}

Oxygen desaturation is the most common complication occurring during intubation in the ICU and is the most common reason for aborting intubation attempts. Therefore, proper preoxygenation is important to prolong the time to desaturation during intubation and increase the chance of the first attempt success at intubation. ${ }^{[21]}$

Three minutes of preoxygenation using noninvasive positive pressure ventilation (NIPPV) delivered by an ICU ventilator using a face mask; mask is more effective at reducing desaturation than by face mask with bag and reservoir. ${ }^{[22]}$

High-flow nasal cannula (HFNC) oxygen delivered at $70 \mathrm{~L} / \mathrm{min}$ through a device capable of providing heated, humidified oxygen has been compared with standard methods of preoxygenation with mixed results. ${ }^{[23,24]}$ Miguel-Montanes et al. showed that HFNC oxygen administered at a flow rate of $60 \mathrm{~L} / \mathrm{min}$ for preoxygenation and continued during the intubation, reduced the incidence of desaturation from $14 \%$ to $2 \%$, compared with nonrebreather facemask preoxygenation. After preoxygenation with NIPPV, the addition of HFNC oxygen during attempts at TI significantly reduces the severity of desaturation. ${ }^{[25]}$

Apneic oxygenation provided through an HFNC during laryngoscopy may decrease desaturation during intubation and may lead to a higher first-attempt success without hypoxemia. ${ }^{[26-28]}$ The use of an apneic oxygenation by simple nasal cannula at $15 \mathrm{~L} / \mathrm{min}$ to prolong the duration of safe apnea after the administration of neuromuscular blockade has been advocated in the ED ${ }^{[28]}$ However, a recent randomized trial did not show benefit of apneic oxygenation during TI in critically ill patients, ${ }^{[29]}$ possibly because the effectiveness of apneic oxygenation in the critically ill patient may be limited by the presence of illness-causing a physiologic shunt. Recently, the addition of supplemental oxygen through a nasal cannula in the presence of mask leaks has been shown to improve the end-tidal $\mathrm{O}_{2}$ during preoxygenation. ${ }^{[30]}$

\section{Hemodynamic stabilization}

Hypotension after intubation is reported in nearly half of the intubated patients in ICU, with cardiovascular collapse occurring in $30 \%$ patients. ${ }^{[31-33]}$ Hemodynamic instability is an independent predictor of death following intubation. ${ }^{[33]}$ Peri-intubation hemodynamic instability has been shown to increase ICU stay and hospital mortality. ${ }^{[31,33-36]}$ These studies highlight the importance of fluid resuscitation in critically ill patients along with preoxygenation, to improve the safety of emergency intubations. In addition, preparedness and prompt treatment of postintubation hypotension with vasopressors and further fluid therapy are important. Although adequate fluid resuscitation can help prevent postintubation hypotension, proper selection of drugs for intubation is equally important.

\section{Selection of pharmacological agents for tracheal intubation}

Drugs such as benzodiazepines, propofol, and thiopental may be used in reduced doses; however, they decrease the systemic vascular resistance, produce myocardial depression 
and may cause precipitous fall in blood pressure, especially in the American Society of Anesthesiologists III-IV patients and those with hypotension. ${ }^{[37-39]}$ Drugs such as etomidate and ketamine are preferred in comparison in ICU. Although there are concerns about transient adrenal insufficiency with etomidate, especially in septic patients, there is no convincing evidence of harm. ${ }^{[40]}$ Ketamine, due to its sympathomimetic effects, helps to maintain blood pressure during intubation. When compared with etomidate, there was no difference in the rate of complications. ${ }^{[41]}$ Ketamine may cause hypertension, tachycardia, increased airway secretions, raised intracranial and intraocular pressure. Unless contraindicated, it should be the preferred induction agent for endotracheal (ET) intubation. Other agents such as opiates, dexmedetomidine, and lignocaine can be used as adjuncts to blunt sympathetic response to laryngoscopy.

The use of neuromuscular blocking agents not only improves the laryngoscopic grade of view but also the overall intubating conditions. The use of neuromuscular blocking agents has been shown to improve first-attempt intubation success with both rapid and delayed sequence intubation, irrespective of the choice of induction agent (ketamine or etomidate), or route of administration used. ${ }^{[42,43]}$ Suxamethonium has been the conventionally used neuromuscular blocking agent of choice, unless contraindicated, due to its fast action facilitating early intubation without the need for ventilation. However, rocuronium at a dose of $1.2 \mathrm{mg} / \mathrm{kg}$ has comparable speed of action and intubating conditions to suxamethonium. ${ }^{[4]}$

\section{Device selection}

Although more widely used in the OR, video laryngoscopy has been shown to increase first-attempt success and improve glottis visualization during intubation in the ICU, ED and in the prehospital setting, even in patients with a predicted difficult airway ${ }^{[45-47]}$ The meta-analysis by De Jong et al..$^{[45]}$ comparing direct laryngoscopy with video laryngoscopy for TI in ICU showed that first-attempt success was twice as much when a video laryngoscope was used.

The NAP4 report of the intensive care and $\mathrm{ED}^{[7]}$ patients identified the nonavailability of appropriate equipment such as the flexible fiberoptic bronchoscope, lack of training to use the equipment, and failure to consider using the right equipment to be the most common issues with use of airway management devices in ICU. This highlights the importance of adequate training regarding airway equipment for ICU doctors and availability of appropriate devices for airway management in the ICU, just as is in the OR.

\section{Rapid sequence induction}

Most of ICU patients are considered to have a full stomach, and securing the airway with a rapid sequence intubation seems logical. Either suxamethonium (if not contraindicated) or rocuronium may be used for neuromuscular blockade. Application of cricoid pressure may make the laryngoscopic view unfavorable. In such situations, cricoid pressure should be partially or completely released to improve the laryngoscopic view and later reapplied. Gentle mask ventilation while applying cricoid pressure before TI can prolong the time to desaturation and may be useful in patients with poor respiratory reserve and sepsis. A second-generation supraglottic airway device (SAD) offers greater protection against aspiration as compared to the first-generation devices ${ }^{[48]}$ and should be inserted if TI fails during a rapid sequence induction. Insertion of SAD insertion may become difficult if cricoid pressure is applied and thus should be released during insertion.

\section{Confirmation of tracheal Intubation}

The NAP4 report ${ }^{[7]}$ showed that failure to use capnography, contributed to 17 deaths or brain damage in ICU. Esophageal intubations and accidental tube displacements accounted for $82 \%$ of events leading to death or brain damage. This report strongly recommends the use of capnography for confirmation of TI in all critically ill patients, irrespective of location.

\section{Human factors and training}

Intubation in ICU is required at any time in the day or night and may often be performed by less experienced practitioner. In addition, considering the altered physiology of the critically ill patents, lesser time to desaturation, and higher risk of complications, these intubations may lead to very stressful situations ${ }^{[6]}$ which may compromise the performance of the operator sometimes. Thus, airway management training should be an integral part of the training of any specialty which deals with critically ill patients. Use of simulation-based training will help enhance both technical and nontechnical skills and improve preparedness for this highly stressful situation. Use of an algorithmic approach and an intubation bundle may further improve performance.

\section{The intubation bundle}

Bundles are a structured way of improving processes of patient care outcomes using a small, straightforward set of evidence-based practices, which when performed collectively and reliably, have proved to improve patient outcomes. Based on the available evidence, Jaber et al.$^{[49]}$ proposed an intubation management protocol. Adherence to the protocol resulted in significantly lesser life-threatening complications such as severe hypoxemia, severe hypotension, or cardiac arrest ( $21 \%$ vs. $34 \%$ ) and also mild to moderate complications ( $9 \%$ vs. $21 \%$ ) compared to a conventional strategy. This bundle has ten components ${ }^{[49]}$ which include the presence of two operators, fluid loading with $500 \mathrm{ml}$ saline, preparation of long-term sedation and preoxygenation for $3 \mathrm{~min}$ with noninvasive ventilation $(100 \%$ oxygen, pressure support ventilation level between 5 and $15 \mathrm{~cm} \mathrm{H}_{2} \mathrm{O}$ to obtain an expiratory tidal volume between 6 and $8 \mathrm{ml} / \mathrm{kg}$, and positive end-expiratory pressure (PEEP) of $5 \mathrm{~cm} \mathrm{H}_{2} \mathrm{O}$ ) in case of acute respiratory failure in the preintubation period. Rapid sequence induction is performed using cricoid pressure with either ketamine or etomidate for induction and suxamethonium or etomidate for neuromuscular blockade. Postintubation components include immediate confirmation of tube placement using capnography, using norepinephrine if the diastolic blood 
pressure remains low, initiation of long-term sedation, and use of protective lung ventilation. While this bundle has not been validated, we believe it is a reasonable protocol for safe $\mathrm{TI}$ in the ICU.

\section{A Stepwise Approach for the Management Tracheal Intubation in the Intensive Care Unit}

The AIDAA proposes a stepwise approach for the management of TI in ICU [Figure 1]. It is important to remember that while following any step in the algorithm, if the oxygen saturation $\left(\mathrm{SpO}_{2}\right)$ is not maintained or starts rapidly falling or bradycardia develops, one can bypass one or more steps and proceed to rescue ventilation and even emergency cricothyrotomy.

\section{Step 1: Preoxygenation and induction of anesthesia}

During intubation, the presence of minimum two persons is required, out of which one should be experienced in airway management. Preoxygenation should be done using noninvasive ventilation with a pressure support ventilation level between 5 and $15 \mathrm{~cm} \mathrm{H}_{2} \mathrm{O}$ to obtain an expiratory

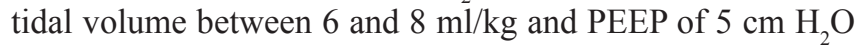
(nasal cannula with an $\mathrm{O}_{2}$ flow of $15 \mathrm{~L} / \mathrm{min}$ may be used in addition when there is a mask leak) or HFNC with $70 \mathrm{~L} / \mathrm{min}$ of oxygen flow should be used. Preintubation fluid loading with $500 \mathrm{~mL}$ of saline should be given in the absence of cardiogenic pulmonary edema. The patient should be anesthetized using ketamine or etomidate and neuromuscular blockade provided with succinylcholine or rocuronium. IPPV may be performed using bag-valve mask with reservoir bag using external PEEP valve set to 5-10 $\mathrm{cm} \mathrm{H}_{2} \mathrm{O}$ PEEP if available or IPPV using the ventilator maintaining a cricoid pressure throughout. Cricoid pressure should be given, but may be partially or completely released if ventilation is inadequate.

\section{Step 2: Laryngoscopy and tracheal intubation}

If mask ventilation is successful proceed with TI using direct or video laryngoscopy. Nasal oxygen using $\mathrm{O}_{2}$ flow of $15 \mathrm{~L} / \mathrm{min}$ or $\mathrm{HFNC} \mathrm{O}_{2}$ should be continued. Do not exceed more than two attempts at intubation and repeat an attempt only if the $\mathrm{SpO}_{2}$ is $\geq 95 \%$. Mask ventilation should be performed between attempts. Optimize position, use external laryngeal manipulations, partially or completely release the cricoid pressure to optimize the laryngoscopic view if required and use a bougie or stylet if required. Between attempts at intubation consider changing the device or technique, rather than repeating the same technique. Maintain depth of anesthesia throughout the intubation attempts. If mask ventilation is not possible, a single attempt at intubation could be made, provided the $\mathrm{SpO}_{2}$ is $\geq 95 \%$. After intubation, confirm proper ET tube position using capnography along with clinical methods.

\section{Step 3: Insert supraglottic airway device to maintain oxygenation}

If two attempts at intubation fail, or after a single attempt at intubation following unsuccessful mask ventilation fails, insert a SAD (preferably a second generation device) and ventilate to maintain oxygenation. Not more than two attempts should be made to insert an SAD and only if the $\mathrm{SpO}_{2}$ is $\geq 95 \%$. Nasal oxygen using $\mathrm{O}_{2}$ flow of $15 \mathrm{~L} / \mathrm{min}$ or $\mathrm{HFNC} \mathrm{O}_{2}$ should be continued during SAD insertion. Perform mask ventilation between the attempts. Consider using a different type or size of SAD during the second attempt. Maintain depth of anesthesia throughout the insertion attempts. Once SAD insertion is successful and oxygenation is maintained consider performing a percutaneous or surgical tracheostomy for further airway management. Intubation through the SAD may be considered, but only under vision using a flexible fiber-optic bronchoscope. Intubation should not be attempted blindly through the SAD if a bronchoscope and the expertise to use it are unavailable.

\section{Step 4: Rescue face mask ventilation}

If ventilation through the SAD fails, continue nasal oxygenation using $\mathrm{O}_{2}$ flow of $15 \mathrm{~L} / \mathrm{min}$ or $\mathrm{HFNC} \mathrm{O}_{2}$. Ensure complete neuromuscular blockade, repeat a muscle relaxant if required. Give one final attempt at face mask ventilation using optimal technique and adjuncts. If rescue face mask ventilation is successful proceed with a percutaneous or surgical tracheostomy. However, if rescue face mask ventilation is unsuccessful, there is "complete ventilation failure." Continue nasal oxygenation using oxygen flow at $15 \mathrm{~L} / \mathrm{min}$ or HFNC $\mathrm{O}_{2}$ and call for additional help. Immediately, start performing emergency cricothyroidotomy before the patient desaturates further.

\section{Step 5: Emergency cricothyroidotomy}

Perform emergency cricothyroidotomy using needle or surgical cricothyroidotomy, based on familiarity and availability of equipment. If needle cricothyroidotomy is performed, maintain oxygenation using pressure regulated jet ventilation, until a tracheostomy is performed. If a wide bore cannula cricothyroidotomy set has been used or an ET tube has been passed through the front of the neck, continue ventilation manually or using a ventilator circuit.

\section{SUMmaRY}

TI in the ICU is a potentially hazardous procedure, most commonly due to failing oxygenation and unstable hemodynamics during emergency intubations. The AIDAA stepwise approach emphasizes the importance of adequate supervision, good preoxygenation with noninvasive ventilation or HFNC oxygen at $60 \mathrm{~L} / \mathrm{min}$, maintenance of hemodynamic stability, use of IPPV with PEEP before intubation, and insufflation of oxygen at $15 \mathrm{~L} / \mathrm{min}$ or $\mathrm{HNFC} \mathrm{O}_{2}$ throughout the period of apnea. SADs have an important role in difficult airway management, and cricothyroidotomy is the procedure of choice when there is complete ventilation failure. We believe that the AIDAA guidelines will help increase the safety of TI in the ICU.

\section{Financial support and sponsorship}

All expenses related to the development of the guidelines were entirely funded by All India Difficult Airway Association. 


\section{AIDAA 2016 Guidelines for Tracheal Intubation in the Intensive Care Unit}

\section{STEP 1 : Preoxygenation and induction of anaesthesia}

- Two persons (one experienced)

- Optimise preoxygenation with one of the following :

- Noninvasive ventilation with $100 \% \mathrm{O}_{2}$, pressure support of $5-15 \mathrm{~cm} \mathrm{H}_{2} \mathrm{O}$ with PEEP of $5 \mathrm{~cm} \mathrm{H}_{2} \mathrm{O}$ for 3 minutes (nasal cannula with $\mathrm{O}_{2}$ flow at $15 \mathrm{~L} / \mathrm{min}$ )

- $\mathrm{HFNC} \mathrm{O}_{2}$ therapy

- Induction - Etomidate or Ketamine with Succinylcholine (if not contraindicated) or Rocuronium

- Use cricoid pressure

- IPPV with bag-valve mask with reservoir bag (use external PEEP valve set to $5-10 \mathrm{~cm} \mathrm{H}_{2} \mathrm{O}$ if available) / IPPV with PEEP using the ventilator

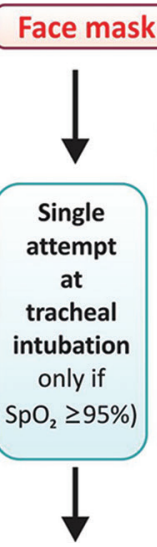

STEP 3 : Insert SAD to maintain oxygenation

- Continue nasal oxygen using $\mathrm{O}_{2}$ flow at $15 \mathrm{~L} / \mathrm{min}$ OR HFNC $\mathrm{O}_{2}$

- Preferably use second generation SAD

- Maximum two attempts (only if $\mathrm{SpO}_{2} \geq 95 \%$ )

- Mask ventilation between attempts

- Consider changing size or type of SAD

- Maintain depth of anaesthesia

Failed ventilation through SAD

\section{STEP 4: Rescue face mask ventilation}

- Continue nasal oxygen using $\mathrm{O}_{2}$ flow at $15 \mathrm{~L} / \mathrm{min}$ OR HFNC $\mathrm{O}_{2}$

- Ensure neuromuscular blockade

- Final attempt at face mask ventilation using optimal technique and adjuncts

Complete Ventilation Failure

\section{$\downarrow \begin{gathered}\text { CALL FOR } \\ \text { ADDITIONAL HELP }\end{gathered}$}

\section{STEP 5: Emergency cricothyroidotomy}

- Continue nasal oxygen using $\mathrm{O}_{2}$ flow at $15 \mathrm{~L} / \mathrm{min}$ OR HFNC $\mathrm{O}_{2}$ and efforts at rescue face mask ventilation

- Perform one of the following techniques

- Surgical cricothyroidotomy

- Wide bore cannula cricothyroidotomy

> Needle cricothyroidotomy (use pressure regulated jet ventilation and attempt to keep the upper airway patent)

This flow chart should be used in conjunction with the text

FOB $=$ Fibreoptic bronchoscope

HFNC $=$ High flow nasal cannula

PEEP $=$ Positive end-expiratory pressure

SAD = Supraglottic airway device

IPPV = Intermittent positive pressure ventilation $\mathrm{SpO}_{2}=$ Oxygen saturation

$\mathrm{O}_{2}=$ Oxygen

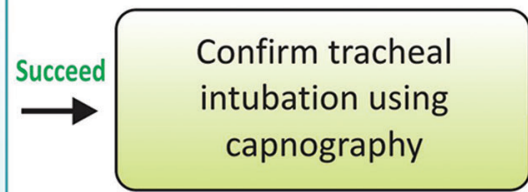

Consider one of the following options :

1. Percutaneous or surgical tracheostomy

2. Intubate through the $S A D$ using a FOB only, provided expertise is available

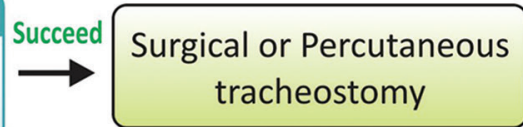

Figure 1: All India Difficult Airway Association 2016 algorithm for the management of tracheal intubation in the Intensive Care Unit. 


\section{Conflicts of interest}

There are no conflicts of interest.

\section{References}

1. Schwartz DE, Matthay MA, Cohen NH. Death and other complications of emergency airway management in critically ill adults. A prospective investigation of 297 tracheal intubations. Anesthesiology 1995;82:367-76

2. Jaber S, Amraoui J, Lefrant JY, Arich C, Cohendy R, Landreau L, et al. Clinical practice and risk factors for immediate complications of endotracheal intubation in the Intensive Care Unit: A prospective, multiple-center study. Crit Care Med 2006;34:2355-61.

3. Griesdale DE, Bosma TL, Kurth T, Isac G, Chittock DR. Complications of endotracheal intubation in the critically ill. Intensive Care Med 2008;34:1835-42.

4. Jabre P, Avenel A, Combes X, Kulstad E, Mazariegos I, Bertrand L, et al . Morbidity related to emergency endotracheal intubation - A substudy of the KETAmine SEDation trial. Resuscitation 2011;82:517-22.

5. Breckwoldt J, Klemstein S, Brunne B, Schnitzer L, Mochmann HC, Arntz HR. Difficult prehospital endotracheal intubation - Predisposing factors in a physician based EMS. Resuscitation 2011;82:1519-24.

6. Divatia JV, Khan PU, Myatra SN. Tracheal intubation in the ICU: Life saving or life threatening? Indian J Anaesth 2011;55:470-5.

7. Cook TM, Woodall N, Harper J, Benger J; Fourth National Audit Project. Major complications of airway management in the UK: Results of the Fourth National Audit Project of the Royal College of Anaesthetists and the Difficult Airway Society. Part 2: Intensive care and emergency departments. Br J Anaesth 2011;106:632-42.

8. Myatra SN, Shah A, Kundra P, Patwa A, Ramkumar V, Divatia JV, et al. All India Difficult Airway Association 2016 guidelines for the management of unanticipated difficult tracheal intubation in adults. Indian J Anaesth 2016;60:885-98.

9. Mort TC. Emergency tracheal intubation: Complications associated with repeated laryngoscopic attempts. Anesth Analg 2004;99:607-13.

10. Martin LD, Mhyre JM, Shanks AM, Tremper KK, Kheterpal S. 3,423 emergency tracheal intubations at a university hospital: Airway outcomes and complications. Anesthesiology 2011;114:42-8.

11. Mayo PH, Hegde A, Eisen LA, Kory P, Doelken P. A program to improve the quality of emergency endotracheal intubation. J Intensive Care Med 2011;26:50-6.

12. Bowles TM, Freshwater-Turner DA, Janssen DJ, Peden CJ; RTIC Severn Group. Out-of-theatre tracheal intubation: Prospective multicentre study of clinical practice and adverse events. Br J Anaesth 2011;107:687-92.

13. Simpson GD, Ross MJ, McKeown DW, Ray DC. Tracheal intubation in the critically ill: A multi-centre national study of practice and complications. Br J Anaesth 2012;108:792-9.

14. Sakles JC, Chiu S, Mosier J, Walker C, Stolz U. The importance of first pass success when performing orotracheal intubation in the emergency department. Acad Emerg Med 2013;20:71-8.

15. Mort TC. The incidence and risk factors for cardiac arrest during emergency tracheal intubation: A justification for incorporating the ASA Guidelines in the remote location. J Clin Anesth 2004;16:508-16.

16. Mallampati SR, Gatt SP, Gugino LD, Desai SP, Waraksa B, Freiberger D, et al. A clinical sign to predict difficult tracheal intubation: A prospective study. Can Anaesth Soc J 1985;32:429-34.

17. Wilson ME, Spiegelhalter D, Robertson JA, Lesser P. Predicting difficult intubation. Br J Anaesth 1988;61:211-6.

18. Levitan RM, Everett WW, Ochroch EA. Limitations of difficult airway prediction in patients intubated in the emergency department. Ann Emerg Med 2004;44:307-13.

19. De Jong A, Molinari N, Terzi N, Mongardon N, Arnal JM, Guitton C, et al. Early identification of patients at risk for difficult intubation in the Intensive Care Unit: Development and validation of the MACOCHA score in a multicenter cohort study. Am J Respir Crit Care Med 2013; 187:832-9.

20. Schmidt UH, Kumwilaisak K, Bittner E, George E, Hess D. Effects of supervision by attending anesthesiologists on complications of emergency tracheal intubation. Anesthesiology 2008;109:973-7.
21. Mosier JM, Hypes CD, Sakles JC. Understanding preoxygenation and apneic oxygenation during intubation in the critically ill. Intensive Care Med 2017;43:226-8

22. Baillard C, Fosse JP, Sebbane M, Chanques G, Vincent F, Courouble P, et al. Noninvasive ventilation improves preoxygenation before intubation of hypoxic patients. Am J Respir Crit Care Med 2006;174:171-7.

23. Vourc'h M, Asfar P, Volteau C, Bachoumas K, Clavieras N, Egreteau PY, et al. High-flow nasal cannula oxygen during endotracheal intubation in hypoxemic patients: A randomized controlled clinical trial. Intensive Care Med 2015;41:1538-48.

24. Miguel-Montanes R, Hajage D, Messika J, Bertrand F, Gaudry S, Rafat C, et al. Use of high-flow nasal cannula oxygen therapy to prevent desaturation during tracheal intubation of intensive care patients with mild-to-moderate hypoxemia. Crit Care Med 2015;43:574-83.

25. Jaber S, Monnin M, Girard M, Conseil M, Cisse M, Carr J, et al. Apnoeic oxygenation via high-flow nasal cannula oxygen combined with non-invasive ventilation preoxygenation for intubation in hypoxaemic patients in the Intensive Care Unit: The single-centre, blinded, randomised controlled OPTINIV trial. Intensive Care Med 2016;42:1877-87.

26. Sakles JC, Mosier JM, Patanwala AE, Arcaris B, Dicken JM. First pass success without hypoxemia is increased with the use of apneic oxygenation during rapid sequence intubation in the emergency department. Acad Emerg Med 2016;23:703-10.

27. Wimalasena Y, Burns B, Reid C, Ware S, Habig K. Apneic oxygenation was associated with decreased desaturation rates during rapid sequence intubation by an Australian helicopter emergency medicine service. Ann Emerg Med 2015;65:371-6.

28. Weingart SD, Levitan RM. Preoxygenation and prevention of desaturation during emergency airway management. Ann Emerg Med 2012;59:165-75.e1.

29. Semler MW, Janz DR, Lentz RJ, Matthews DT, Norman BC, Assad TR, et al. Randomized trial of apneic oxygenation during endotracheal intubation of the critically Ill. Am J Respir Crit Care Med 2016;193:273-80.

30. Hayes-Bradley C, Lewis A, Burns B, Miller M. Efficacy of nasal cannula oxygen as a preoxygenation adjunct in emergency airway management. Ann Emerg Med 2016;68:174-80.

31. Heffner AC, Swords D, Kline JA, Jones AE. The frequency and significance of postintubation hypotension during emergency airway management. J Crit Care 2012;27:417.e9-13.

32. Perbet S, De Jong A, Delmas J, Futier E, Pereira B, Jaber S, et al. Incidence of and risk factors for severe cardiovascular collapse after endotracheal intubation in the ICU: A multicenter observational study. Crit Care 2015;19:257.

33. Green RS, Turgeon AF, McIntyre LA, Fox-Robichaud AE, Fergusson DA, Doucette S, et al. Postintubation hypotension in Intensive Care Unit patients: A multicenter cohort study. J Crit Care 2015;30:1055-60.

34. Green RS, Edwards J, Sabri E, Fergusson D. Evaluation of the incidence, risk factors, and impact on patient outcomes of postintubation hemodynamic instability. CJEM 2012;14:74-82.

35. Kim WY, Kwak MK, Ko BS, Yoon JC, Sohn CH, Lim KS, et al. Factors associated with the occurrence of cardiac arrest after emergency tracheal intubation in the emergency department. PLoS One 2014;9:e112779.

36. Smischney NJ, Demirci O, Ricter BD, Hoeft CC, Johnson LM, Ansar S, et al. Vasopressor use as a surrogate for post-intubation hemodynamic instability is associated with in-hospital and 90-day mortality: A retrospective cohort study. BMC Res Notes 2015;8:445.

37. Shah SB, Chowdhury I, Bhargava AK, Sabbharwal B. Comparison of hemodynamic effects of intravenous etomidate versus propofol during induction and intubation using entropy guided hypnosis levels. J Anaesthesiol Clin Pharmacol 2015;31:180-5.

38. Kaushal RP, Vatal A, Pathak R. Effect of etomidate and propofol induction on hemodynamic and endocrine response in patients undergoing coronary artery bypass grafting/mitral valve and aortic valve replacement surgery on cardiopulmonary bypass. Ann Card Anaesth 2015;18:172-8.

39. Reich DL, Hossain S, Krol M, Baez B, Patel P, Bernstein A, et al. Predictors of hypotension after induction of general anesthesia. Anesth 
Analg 2005;101:622-8.

40. Gu WJ, Wang F, Tang L, Liu JC. Single-dose etomidate does not increase mortality in patients with sepsis: A systematic review and meta-analysis of randomized controlled trials and observational studies. Chest 2015;147:335-46.

41. Jabre P, Combes X, Lapostolle F, Dhaouadi M, Ricard-Hibon A, Vivien $\mathrm{B}$, et al. Etomidate versus ketamine for rapid sequence intubation in acutely ill patients: A multicentre randomised controlled trial. Lancet 2009;374:293-300.

42. Mosier JM, Sakles JC, Stolz U, Hypes CD, Chopra H, Malo J, et al. Neuromuscular blockade improves first-attempt success for intubation in the Intensive Care Unit. A propensity matched analysis. Ann Am Thorac Soc 2015;12:734-41.

43. Lyon RM, Perkins ZB, Chatterjee D, Lockey DJ, Russell MQ; Kent, Surrey and Sussex Air Ambulance Trust. Significant modification of traditional rapid sequence induction improves safety and effectiveness of pre-hospital trauma anaesthesia. Crit Care 2015;19:134.

44. Marsch SC, Steiner L, Bucher E, Pargger H, Schumann M, Aebi T, et al. Succinylcholine versus rocuronium for rapid sequence intubation in intensive care: A prospective, randomized controlled trial. Crit Care
2011;15:R199.

45. De Jong A, Molinari N, Conseil M, Coisel Y, Pouzeratte Y, Belafia F, et al. Video laryngoscopy versus direct laryngoscopy for orotracheal intubation in the Intensive Care Unit: A systematic review and meta-analysis. Intensive Care Med 2014;40:629-39.

46. Sakles JC, Patanwala AE, Mosier JM, Dicken JM. Comparison of video laryngoscopy to direct laryngoscopy for intubation of patients with difficult airway characteristics in the emergency department. Intern Emerg Med 2014;9:93-8.

47. Silverberg MJ, Li N, Acquah SO, Kory PD. Comparison of video laryngoscopy versus direct laryngoscopy during urgent endotracheal intubation: A randomized controlled trial. Crit Care Med 2015;43:636-41.

48. Cook TM, Kelly FE. Time to abandon the 'vintage' laryngeal mask airway and adopt second-generation supraglottic airway devices as first choice. Br J Anaesth 2015;115:497-9.

49. Jaber S, Jung B, Corne P, Sebbane M, Muller L, Chanques G, et al. An intervention to decrease complications related to endotracheal intubation in the Intensive Care Unit: A prospective, multiple-center study. Intensive Care Med 2010;36:248-55. 